\title{
Correction for Radiation Dry Bias Found in RS92 Radiosonde Data during the MISMO Field Experiment
}

\author{
Kunio Yoneyama ${ }^{1}$, Mikiko Fujita ${ }^{1}$, Naoki Sato ${ }^{1}$, Masatomo Fujiwara ${ }^{2}$, Yoichi Inai ${ }^{2}$, \\ and Fumio Hasebe ${ }^{2}$ \\ ${ }^{1}$ Institute of Observational Research for Global Change, JAMSTEC, Yokosuka, Japan \\ ${ }^{2}$ Graduate School of Environmental Science, Hokkaido University, Sapporo, Japan
}

\begin{abstract}
Atmospheric soundings using the Vaisala RS92 radiosonde were intensively conducted during the field experiment MISMO (Mirai Indian Ocean cruise for the Study of the MJO-convection Onset) in the central and eastern equatorial Indian Ocean from October to December 2006. By comparing the RS92 relative humidity data with that from the Meteolabor Snow White (SW) chilled-mirror dew/frost-point hygrometers launched on the same ship around the local noon time, the dry bias was found to increase significantly with height. In addition, it was also revealed that the dry bias had a clear diurnal variation with its maximum at local noon and near-zero at night from the comparison of precipitable water vapor (PWV) with that derived from the shipboard Global Positioning System (GPS) data. Therefore, the dry bias of the RS92 data could be attributed to a solar radiation-induced error that was recently discussed by Vömel et al. (2007).

In this study, we developed a correction scheme for the MISMO RS92 humidity data as a function of pressure and local time using SW data, and then confirmed its validity with GPS-derived PWV.
\end{abstract}

\section{Introduction}

Radiosonde observations provide basic and useful information on the atmospheric condition. However, many researchers found dry bias in humidity data and extensive efforts have been made to identify the error sources and to reduce the bias from original data (e.g., Guichard et al. 2000; Wang et al. 2002; Nakamura et al. 2004; Miloshevich et al. 2006; Häberli 2006). Recently, Vömel et al. (2007) showed a large solar radiationinduced dry bias in humidity data obtained by the Vaisala RS92 radiosonde which is now widely used in the world. This dry bias is mainly caused due to the lack of radiation protective shields for RS92 model. While manufacturers should improve the skill to produce reliable instruments, researchers should also be aware of data accuracy for precise process studies as well as climate studies.

In October-December 2006, the field experiment MISMO (Yoneyama et al. 2006) took place in the equatorial Indian Ocean centered at $0^{\circ}, 80.5^{\circ} \mathrm{E}$ using the research vessel Mirai, and a total of 329 Vaisala RS92 radiosondes were launched. During the same period, observations using the Meteolabor "Snow White (SW)" chilled-mirror dew/frost-point hygrometers were conducted 15 times, and most of them (14 times) were launched near local noon. In addition, precipitable water vapor (PWV) from the Global Positioning System (GPS) measurements of zenith tropospheric delay (ZTD) was also continuously observed during the entire cruise. As will be shown later, comparison of the RS92 humidity

Corresponding author: Kunio Yoneyama, Institute of Observational Research for Global Change (IORGC), Japan Agency for Marine-Earth Science and Technology (JAMSTEC), 2-15, Natsushima-cho, Yokosuka 237-0061, Japan. E-mail: yoneyamak @jamstec.go.jp. @2008, the Meteorological Society of Japan. data with the SW humidity data and the GPS-derived PWV data showed a clear dry bias only in the daytime, suggesting a solar radiation-induced dry bias.

In general, the influence of solar radiation on humidity data is larger in the upper troposphere. However, the significant difference of PWVs between GPS and radiosonde indicates that humidity data in the middle and lower troposphere are also affected. As the main purpose of MISMO was to observe the atmospheric condition when convection in the Madden- Julian Oscillation (MJO; Madden and Julian 1994) was initiated, we cannot neglect such an error in humidity data.

Hence, this study evaluated and corrected the dry bias of RS92 humidity data taken during the MISMO experiment using data from other different observations. First, we estimated and reduced the daytime dry bias by utilizing the Meteolabor SW hygrometer data. We then evaluated the corrected humidity data by comparing PWV with that derived from GPS data.

\section{Data}

During the MISMO field experiment, the Mirai stayed within the range of $2^{\circ} \mathrm{S}-3^{\circ} \mathrm{N}, 79^{\circ} \mathrm{E}-82^{\circ} \mathrm{E}$ from October 22 through November 25, 2006. Atmospheric soundings using the Vaisala RS92 radiosonde were conducted every 3 hours (277 times) during this period, and other 52 soundings were conducted along the equator in December. During the stationary observation period (i.e., first period), fifteen special soundings which included the Meteolabor SW hygrometers were also carried out to investigate the transport and dehydration processes around the tropical tropopause. Since the SW hygrometer directly measures dew/frost-point based on a chilled-mirror principle, SW data have been used as a reference for evaluation of the accuracy of humidity data taken by a capacitive thin-film sensor including the Vaisala radiosondes (e.g., Wang et al. 2003). Detailed technical characteristics of the Meteolabor SW hygrometer and the Vaisala RS92 radiosonde were examined in several studies (e.g., Fujiwara et al. 2003; Vömel et al. 2003; Miloshevich et al. 2006). Since the SW hygrometers were launched separately with the RS92 radiosonde, the RS92 data at the nearest time were compared with the SW data (Table 1). For comparison, both RS92 and SW data were converted onto 5-hPa interval data from different sampling time data sets. Note that all the RS92 radiosondes used in the MISMO were the latest model, which can be confirmed from their serial numbers listed in Table 1 (i.e., First three characters (YWW) of serial number indicate the calibration year ( $Y ; B=2006)$ and week number (WW) (e.g., Miloshevich et al. 2004). So, in this case sensor calibrations at the manufacturer were conducted in the weeks from 34 to 38 of the year 2006 , that is $1-2$ months prior to the experiment.).

In addition to the radiosonde observation, continuous PWV measurement was carried out using GPS receiver on the ship (Rocken et al. 2005, 2006). During the entire cruise, the position of GPS antenna and ZTD were measured every 5 seconds. For data processing, global mapping function that was recently provided by 
Boehm et al. (2006) was used. PWV was then estimated from ZTD with surface pressure and temperature data (Bevis et al. 1992). Since the GPS-derived PWV is one of the most reliable parameters and is often used to evaluate the quality of radiosonde humidity data (e.g., Nakamura et al. 2004; Van Baelen et al. 2005; Wang and Zhang 2007, manuscript submitted to J. Climate), comparison between PWVs derived from observed/corrected radiosonde humidity data and from GPS was made to evaluate the correction. In this study, hourlymean GPS-derived PWV data were used, since it took about one hour for radiosonde sounding to observe the entire troposphere.

\section{Dry bias and its correction}

Figure 1 shows the relative difference of relative humidity (RH) between RS92 and SW as a function of pressure height for 14 cases (No. 1-14 in Table 1). The observations were conducted near local noon when the influence of solar radiation was large. It is obvious that RS92 data have a dry bias compared to SW data and their difference increases with height. While the difference is almost zero at the surface, it reaches over $40 \%$ in the upper troposphere above 150-hPa level. Figure 2 illustrates the RH profiles of SW and RS92 for the case of local evening launch (No. 15 in Table 1). It shows no significant dry bias (mean difference calculated over the troposphere is $0.6 \% \mathrm{RH}$ ). These results strongly suggest that the dry bias found in Fig. 1 is attributed to the influence of solar radiation as discussed by Vömel et al. (2007). It is worth noting that the mean bias at the surface is almost zero in this study, while relative difference of about $9 \%$ was found in the study of Vömel et al. (2007, see Figs. 6 and 8 of their paper). At present, we cannot provide a definitive explanation on this difference. One possible factor, however, may relate to the difference of observational location; one is on land, while the other is at sea, because of their different albedos. Further studies may be needed. Note that we launched radiosondes from the launcher system situated in the " sea-container" on-board the Mirai. Thus, there should be no influence of the so-called sensor arm heating error (e.g., Wang et al. 2002) which is attributed to the radiation heating of the senor arm prior to the launch and influences the data only taken during the first minute from the launch.

As mentioned, Figure 1 is obtained from observations conducted near local noon, and we do not have enough data at other local times for SW data. Thus, we compare the PWVs derived from RS92 and from GPS to examine the diurnal variation of dry bias. Figure $3 \mathrm{a}$ shows the difference of PWV between RS92 and GPS as a function of local standard time (LST; UTC+5). For comparison, all the RS92 and GPS data from October 22 through November 25 were used. One should note that similar results were obtained in both cases, when we limited the analysis period to the one between October 29 and November 15 when SWs were launched, and when we extended the period to December 10 including entire 329 radiosonde data (not shown). In Fig. 3a, the difference is significant only in the daytime, suggesting again that the dry bias is primarily caused by solar radiation. While the daily-mean difference of PWV is -1.6 $\mathrm{mm}$ with $+/-2.6 \mathrm{~mm}$ standard deviation, their mean difference at $1100 \mathrm{LST}$ and $1400 \mathrm{LST}$ are $-3.7 \mathrm{~mm}$ and -4.1 $\mathrm{mm}$, respectively. Note that we also calculated the PWV from $14 \mathrm{SW}$ near local noon data to confirm the relationship between two different data sets. In result, we confirmed that they showed a good agreement having their mean difference (SW-derived PWV minus GPSderived PWV) of $-0.5 \mathrm{~mm}$ with $+/-1.5 \mathrm{~mm}$ standard deviation.

Based on these results as well as the work of Vömel et al. (2007), we will then determine the correction factor
Table 1. Launch time of RS92 and SW used for comparison. Solar zenith angle indicates the value when RS92 radiosonde was launched.

\begin{tabular}{|c|c|c|c|c|c|c|}
\hline \multirow{2}{*}{ No. } & \multicolumn{3}{|c|}{ Time (LST) } & \multirow{2}{*}{$\begin{array}{l}\text { Nominal } \\
\text { Time }\end{array}$} & \multirow{2}{*}{$\begin{array}{c}\text { RS92 } \\
\text { Serial No. }\end{array}$} & \multirow{2}{*}{$\begin{array}{c}\text { Solar Zenith } \\
\text { Angle (deg) }\end{array}$} \\
\hline & Day & SW & RS92 & & & \\
\hline 1 & Oct. 29 & $12: 02$ & $10: 47$ & $11: 00$ & B3540428 & 15.9 \\
\hline 2 & Oct. 30 & $14: 01$ & $13: 25$ & $14: 00$ & B3551054 & 33.5 \\
\hline 3 & Nov. 1 & $11: 10$ & $10: 30$ & $11: 00$ & B3550610 & 19.2 \\
\hline 4 & Nov. 2 & $11: 12$ & $10: 30$ & $11: 00$ & B3450300 & 19.4 \\
\hline 5 & Nov. 3 & $11: 15$ & $10: 30$ & $11: 00$ & B3551140 & 19.7 \\
\hline 6 & Nov. 4 & $11: 17$ & 11:02 & $11: 00$ & B3551142 & 16.1 \\
\hline 7 & Nov. 7 & $13: 00$ & $13: 29$ & $14: 00$ & B3550592 & 35.3 \\
\hline 8 & Nov. 8 & $14: 00$ & $13: 30$ & $14: 00$ & B3550725 & 35.7 \\
\hline 9 & Nov. 9 & $14: 00$ & $13: 30$ & $14: 00$ & B3551261 & 35.8 \\
\hline 10 & Nov. 11 & $11: 12$ & $10: 30$ & $11: 00$ & B3550625 & 21.6 \\
\hline 11 & Nov. 12 & $11: 13$ & $10: 45$ & $11: 00$ & B3551073 & 19.9 \\
\hline 12 & Nov. 13 & 11:09 & $10: 47$ & $11: 00$ & В3550953 & 19.9 \\
\hline 13 & Nov. 14 & $11: 13$ & $10: 31$ & $11: 00$ & B3610667 & 22.1 \\
\hline 14 & Nov. 15 & $11: 10$ & $10: 30$ & $11: 00$ & B3611007 & 22.5 \\
\hline 15 & Nov. 20 & $17: 02$ & $16: 41$ & $17: 00$ & B3830442 & 80.0 \\
\hline
\end{tabular}

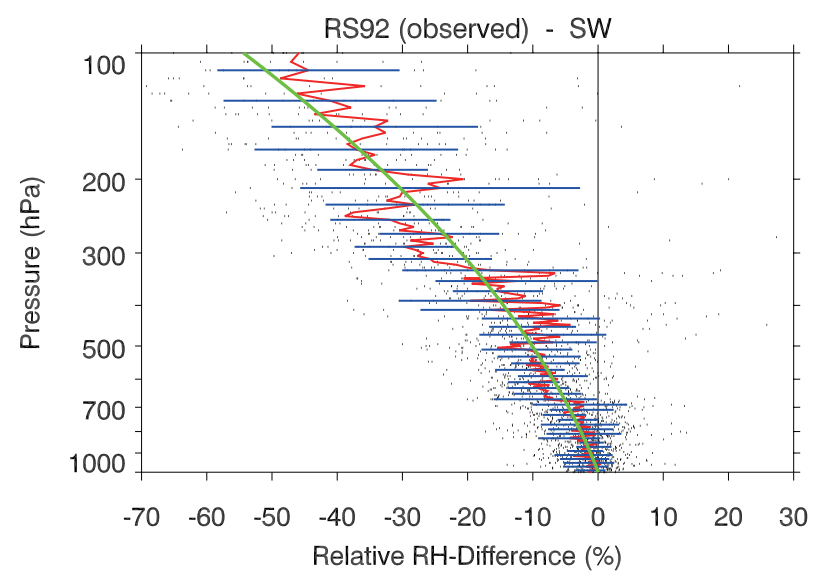

Fig. 1. Relative difference between RS92 RH and SW RH (= 100 $\times\left(\mathrm{RH}_{\mathrm{Rs} 92}-\mathrm{RH}_{\mathrm{sw}}\right) / \mathrm{RH}_{\mathrm{sw}}$, black dot). Results are shown for 14 sets of near local noon observation. The red line indicates the mean profile, and blue horizontal lines indicate the standard deviations. The green curve indicates the profile obtained by a polynomial fitting to the mean profile. See text for details.

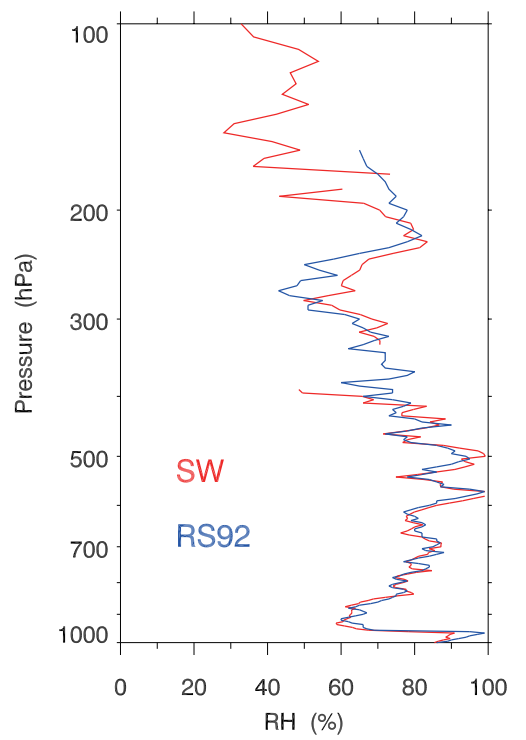

Fig. 2. RH profiles observed by SW (red) and RS92 (blue) which were launched in the local evening (No. 15 in Table 1). 
(a) RS92 (observed) - GPS

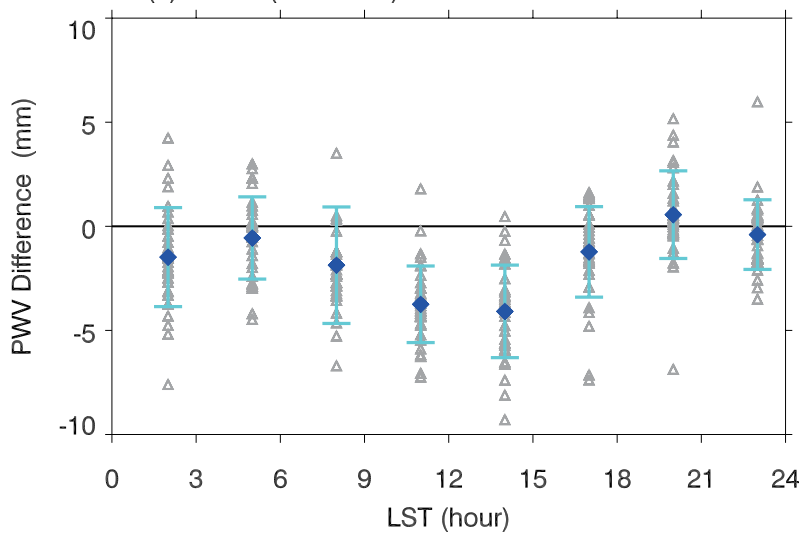

(b) RS92 (corrected) - GPS

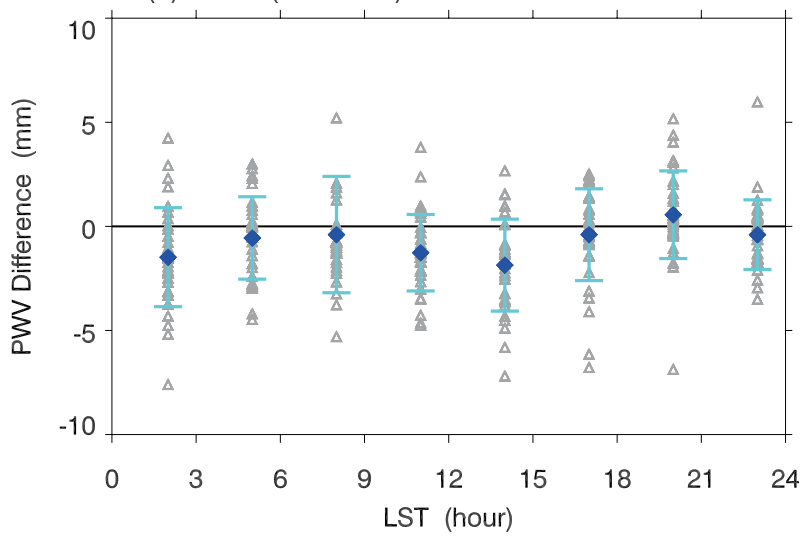

Fig. 3. PWV difference (gray triangle) between RS92 and GPS data (RS92 minus GPS) as a function of LST for RS92 data (a) before, and (b) after the correction. Blue diamond mark indicates the mean value and light blue bar indicates standard deviation. As for the correction, see the text.

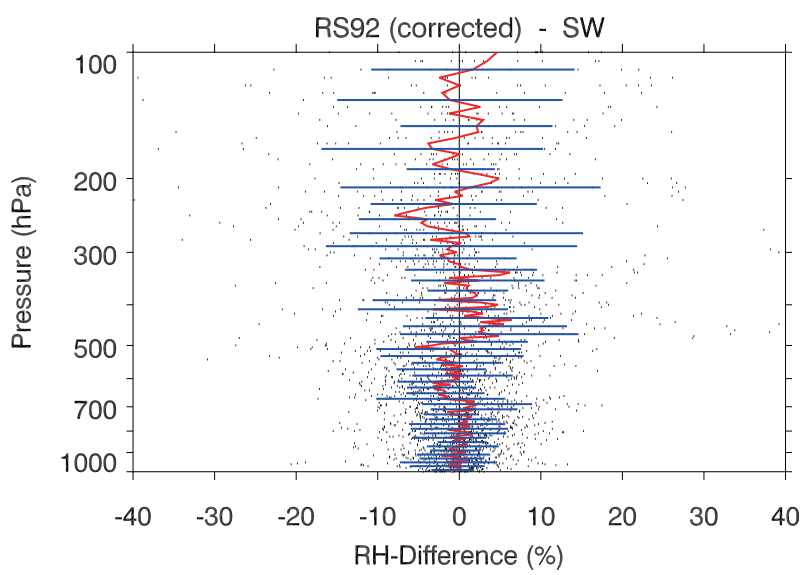

Fig. 4. Difference of RH between corrected RS92 and SW data (black dots). The red line indicates the mean difference and blue lines indicate the standard deviations.

for the MISMO RS92 humidity data using SW data.

First, as shown in the vertical profile of relative difference of $\mathrm{RH}$ in Fig. 1, we obtained the correction profile, $\mathrm{RH}_{\mathrm{dif}}$, by applying a polynomial fitting (green solid line) to the mean profile (red solid line) as a function of pressure $P$ in hPa as follows.

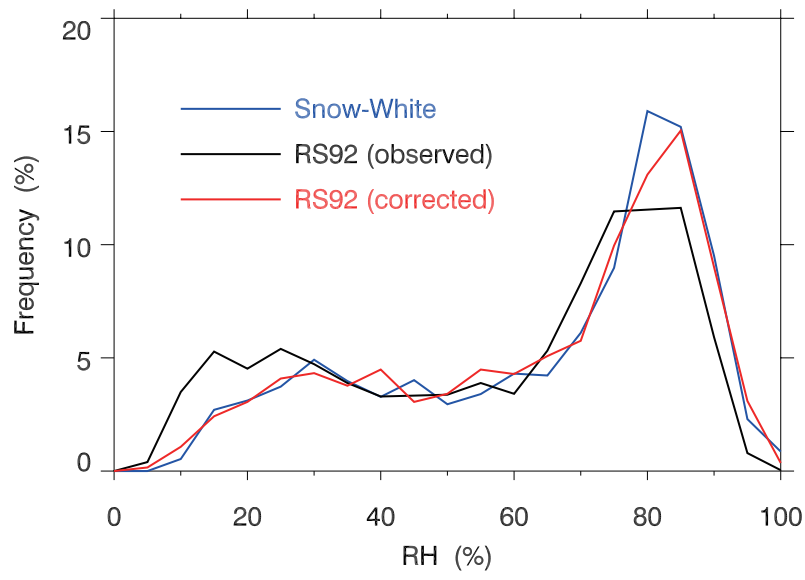

Fig. 5. Frequency distributions of $\mathrm{RH}$ binned by $5 \%$ obtained from SW (blue), observed RS92 (black), and corrected RS92 (red) for 14 cases (No. 1-14 in Table 1).

$\mathrm{RH}_{\mathrm{dif}}=-5.61(\ln P)^{2}+88.17(\ln P)-341.51$.

Note that in this study the time-lag correction (Miloshevich et al. 2004) was not applied, since we did not have data on sensor time-constant. However, as Vömel et al. (2007) mentioned, the time-lag error became noticeable at the uppermost troposphere. Therefore, we could obtain Eq. (1) using only the data below the 150$\mathrm{hPa}$ level. Since the solar radiation is primarily a function of solar zenith angle, we assume that the correction factor is proportional to the solar zenith angle $\theta$ as,

$c=\cos \theta / \cos \theta_{m}$,

where $c$ is a multiple coefficient for correction profile $\mathrm{RH}_{\text {dif }}$ and $\theta_{m}$ is the mean solar zenith angle of 14 data $\left(=24.1^{\circ}\right.$, Table 1$) \cdot c$ is set to zero at nighttime data. Solar zenith angle $\theta$ is obtained from the local time and position for each radiosonde observation. Using these correction factors, the corrected $\mathrm{RH}, \mathrm{RH}_{\text {cor }}$, can be obtained from,

$\mathrm{RH}_{\text {cor }}=\left(100 /\left(100+c \times \mathrm{RH}_{\text {dif }}\right)\right) \times \mathrm{RH}_{\text {obs }}$,

where $\mathrm{RH}_{\text {obs }}$ is the observed $\mathrm{RH}$.

As shown in Fig. 4, where the mean difference between the corrected RS92 data and SW data varies around 0\% through the entire troposphere and it is much smaller than the designed accuracy of radiosonde data, the corrections were properly conducted. The result of correction for all sounding data can be evaluated by comparing the frequency distributions of RH binned by 5\% between observed/corrected RS92 data and SW data (Fig. 5). The frequency distribution of RS92 RH data better agrees with that of SW RH after the correction. In the higher $\mathrm{RH}$ range (mainly corresponding to the lower troposphere), the peak of frequency is located at 70-85\% in the observed RS92 data. However, it shifts to $80-90 \%$ in the corrected one. In the lower RH range (corresponding to the higher troposphere), on the other hand, a peak at $10-20 \%$ in the observed data almost disappeared in the corrected one.

In order to evaluate the correction using different data source, PWV was recalculated using corrected RS92 humidity data and compared with GPS-derived PWV (Fig. 3b). Although there still remain small dry biases in daytime data (1100 and 1400 LST), their mean differences $(-1.3 \mathrm{~mm}$ at $1100 \mathrm{LST}$ and $-1.8 \mathrm{~mm}$ at 1400 LST) are comparable to that of nighttime data. As for the morning (0800 LST) and evening (1700 LST) cases, their differences become close to zero. Note that we confirmed the correction without regard to the solar zenith 
angle dependence expressed as Eq. (2). While we could also obtain similar results for near local noon data, morning and evening data show rather wet bias (not shown). Therefore, taking Eq. (2) into the correction scheme is effective mainly for low solar zenith angle data. As for the remaining differences, it can be attributed to various possible factors such as spatial and temporal sampling error for the two different measurements, uncertainties in GPS-derived PWV, insufficient correction scheme without calibration and time-lag corrections (Miloshevich et al. 2006), and so on. However, in general, the present results show the good correspondence of PWVs derived from different data sources.

\section{Summary and concluding remarks}

This paper described the dry bias found in Vaisala RS92 radiosonde data obtained during the MISMO field experiment in October-December 2006. First, a correction scheme was developed using Meteolabor SW chilled-mirror hygrometer data, and then the results of correction were evaluated using GPS-derived PWV. In this study, although we had only near local noon SW data, correction was applied to all daytime humidity data by assuming that solar radiation error was proportional to solar zenith angle. Since independent measurements (SW and GPS) showed a consistent result, it could be regarded that the correction scheme developed in this study including the assumption of Eq. (2) was properly performed. In other words, if GPS-derived PWV data which are much easier to obtain than simultaneous chilled-mirror hygrometer data are available, it is possible to confirm the existence of dry bias in Vaisala RS92 data, and it might be possible to reduce them using the relationship obtained in this study from SW data. Similar results (bias at the surface is almost zero, and about $30 \%$ at 150 -hPa level) were obtained in the comparison between RS92 and SW data of 11 quasisimultaneous observations during another Mirai MR0408 cruise that took place off Palau Islands in the tropical western Pacific Ocean from December 2004 to January 2005 (not shown here, the cruise report of MR04-08 is available at http://www.jamstec.go.jp/mirai/).

As noted in Yoneyama et al. (2008, manuscript submitted to Bull. Amer. Meteor. Soc.), MISMO data have been opened to public through the MISMO web site at http://www.jamstec.go.jp/iorgc/mismo/ since January 2008 , so that any researchers can use these data for meteorological and climatological studies over the Indian Ocean. As for the radiosonde data, corrected data shown in this study are available for use.

\section{Acknowledgments}

The authors would like to express their sincere thanks to technical staff of Global Ocean Development Inc. for their observation support on-board the Mirai. They are also grateful to Dr. Junhong Wang of the National Center for Atmospheric Research for providing useful comments on dry bias. Thanks are extended to Ms. N. Miyamoto for her assistance with the preparation of this manuscript. Comments from two anonymous reviewers helped to improve the manuscript.

\section{References}

Bevis, M., S. Businger, T. A. Herring, C. Rocken, R. A. Anthes, and R. H. Ware, 1992: GPS meteorology: Remote sensing of atmospheric water vapor using the Global Positioning System. J. Geophys. Res., 97, 15787-15801.
Boehm, J., A. Niell, P. Tregoning, and H. Schuh, 2006: Global Mapping Function (GMF): A new empirical mapping function based on numerical weather model data. Geophys. Res. Lett., 33, L07304, doi:10.1029/2005GL 025546.

Fujiwara, M., M. Shiotani, F. Hasebe, H. Vömel, S. J. Oltmans, P. W. Ruppert, T. Horinouchi, and T. Tsuda, 2003: Performance of the Meteolabor "Snow White" chilled-mirror hygrometer in the tropical troposphere: Comparisons with the Vaisala RS80 A/H-Humicap sensors. J. Atmos. Oceanic Technol., 20, 1534-1542.

Guichard, F., D. B. Parsons, and E. R. Miller, 2000: Thermodynamic and radiative impact of the correction of sounding humidity bias in the Tropics. J. Climate, 13, 3611-3624.

Häberli, C., 2006: Assessment, correction and impact of the dry bias in radiosonde humidity data during the MAP SOP. Quart. J. Roy. Meteor. Soc., 132, 2827-2852.

Madden, R. A., and P. P. Julian, 1994: Observations of the 4050-day tropical oscillation - A review. Mon. Wea. Rev., 122, 814-837.

Miloshevich, L. M., A. Paukkunen, H. Vömel, and S. J. Oltmans, 2004: Development and validation of a time-lag correction for Vaisala radiosonde humidity measurements. J. Atmos. Oceanic Technol., 21, 1305-1327.

Miloshevich, L. M., H. Vömel, D. N. Whiteman, B. M. Lesht, F. J. Schmidlin, and F. Russo, 2006: Absolute accuracy of water vapor measurements from six operational radiosonde types launched during AWEX-G and implications for AIRS validation. J. Geophys. Res., 111, D09S10, doi: 10.1029/2005JD006083.

Nakamura, H., H. Seko, Y. Shoji, Aerological Observatory, and Meteorological Instruments Center, 2004: Dry biases of humidity measurements from the Vaisala RS80-A and Meisei RS2-91 radiosondes and from ground-based GPS. J. Meteor. Soc. Japan, 82, 277-299.

Rocken, C., J. Johnson, T. Van Hove, and T. Iwabuchi, 2005: Atmospheric water vapor and geoid measurements in the open ocean with GPS. Geophys. Res. Lett., 32, L12813, doi:10.1029/2005GL022573.

Rocken, C., Z. Lukes, L. Mervart, J. Johnson, T. Iwabuchi, and M. Kanzaki, 2006: Real-time ionospheric and atmospheric corrections for wide area single frequency carrier phase ambiguity resolution. Proc. ION-GNSS 19th Intl. Technical Meeting of the Satellite Division, Inst. of Navigation, Fort Worth, Texas. 1208-1218.

Van Baelen, J., J.-P. Aubagnac, and A. Dabas, 2005: Comparison of near-real time estimates of integrated water vapor derived with GPS, radiosondes, and microwave radiometer. J. Atmos. Oceanic Technol., 22, 201-210.

Vömel, H., M. Fujiwara, M. Shiotani, F. Hasebe, S. J. Oltmans, and J. E. Barnes, 2003: The behavior of the Snow White chilled-mirror hygrometer in extremely dry conditions. $J$. Atmos. Oceanic Technol., 20, 1560-1567.

Vömel, H., H. Selkirk, L. Miloshevich, J. Valverde-Canossa, J. Valdés, E. Kyrö, R. Kivi, W. Stolz, G. Peng, and J. A. Diaz, 2007: Radiation dry bias of the Vaisala RS92 humidity sensor. J. Atmos. Oceanic Technol., 24, 953-963.

Wang, J., H. L. Cole, D. J. Carlson, E. R. Miller, K. Beierle, A. Paukkunen, and T. K. Laine, 2002: Corrections of humidity measurement errors from the Vaisala RS80 Radiosonde-application to TOGA COARE data. J. Atmos. Oceanic Technol., 19, 981-1002.

Wang, J., D. J. Carlson, D. B. Parsons, T. F. Hock, D. Lauritsen, H. L. Cole, K. Beierle, and E. Chamberlain, 2003: Performance of operational radiosonde humidity sensors in direct comparison with a chilled dew-point hygrometer and its climate implication. Geophys. Res. Lett., 30, 1860, doi: 10.1029/2003GL016985.

Yoneyama, K., Y. Masumoto, Y. Kuroda, M. Katsumata, and K. Mizuno, 2006: MISMO: Mirai Indian Ocean cruise for the Study of the MJO-convection Onset. CLIVAR Exchanges, 39, 8-10, 16. (Available from http://www.clivar.org/)

Manuscript received 31 October 2007, accepted 6 February 2008 SOLA: http://www.jstage.jst.go.jp/browse/sola/ 